\title{
A guarda compartilhada de animais domésticos no Brasil
}

\author{
Pet's shared custody in Brazil \\ La custodia compartida de animales domésticos en Brasil
}

Recebido: 17/06/2021 | Revisado: 25/06/2021 | Aceito: 29/06/2021 | Publicado: 13/07/2021

\author{
Elidsandra Oliveira da Silva \\ ORCID: https://orcid.org/0000-0003-4592-834X \\ Faculdade Assis Grugacz, Brasil \\ E-mail: elidsandra@uol.com.br \\ Eduardo Maffei \\ ORCID: https://orcid.org/0000-0002-8302-3843 \\ Faculdade Assis Grugacz, Brasil \\ E-mail:maffei.adv@hotmail.com
}

\begin{abstract}
Resumo
Abordar-se-ão o status jurídico do animal não humano no Ordenamento Jurídico Brasileiro, além da senciência do animal não humano, bem como o seu lugar no âmbito familiar sobre à luz do conceito contemporâneo de família multiespécie, a qual compreende o animal não humano como um dos membros da família humana. O fato dos animais não humanos serem considerados como sujeitos de direito pela família multiespécie justifica o pleito pela guarda compartilhada de animais domésticos no momento da dissolução conjugal. Porém, ainda que cientificamente declarados como sencientes e assim também os vistos pela sociedade, inexiste lei que tutele os seus direitos no âmbito familiar. Desta forma, o Poder Judiciário cumula entendimentos divergentes ao tratar do direito de guarda compartilhada do animal doméstico, ora por analogia, o trata como sujeito de direito, ora como impõe a lei, nos termos do art. 82 do Código Civil, o trata como mero objeto. Portanto, enquanto não houver lei que dê aos animais não humanos um status que lhe confira direitos, bem provável que não haverá um entendimento pacificado no que diz respeito ao direito de guarda compartilhada de animais domésticos.
\end{abstract}

Palavras-chave: Animais de estimação; Senciência; Família multiespécie; Direito do animal; Guarda compartilhada de animais.

\begin{abstract}
It will approach the juridical status of non-human animals in the Brazilian legal order, further the sentience of the nonhuman animal, as well as your place in the family environment using the contemporary concept of multispecies family, in which we understand the non-human animals as a member of the family. The fact of the non-human animals being considering as legal subjects by their multispecies family justify the plea for the shared custody in the marital dissolution moment. But even if they are scientifically and socially declared sentients. There isn't a law to protect them inside the family environment. So, the judiciary cumulate different comprehensions to threat the pet's shared custody right: sometimes it uses the analogy and considers them a legal subject and sometimes it does as the law says, according to article 82 of the Civil Code it threats them as objects. Therefore, while it doesn't exist a law giving the non-human animals an appropriate status which assure their rights, it's probable that there won't be a pacific understanding as far as the pet's shared custody is concern.
\end{abstract}

Keywords: Pets; Sentience; Multispecies family; Animals rights; Pet's shared custody.

\section{Resumen}

Abordarán el status jurídico del animal no humano en el Ordenamiento Jurídico Brasileño, además de la sintiencia del animal no humano, bien como el lugar en el círculo familiar, sobre la luz del concepto contemporáneo de familia multiespecie, la cual comprende el animal no humano como miembro de la familia humana. El hecho de que los animales no humanos sean considerados como sujetos de derecho por la familia multiespecie justifica la elección por la custodia compartida de los animales domésticos en el momento de la disolución matrimonial. Pero, aunque científicamente declarados como sintiencia y así también los vistos por la sociedad, deja de existir la ley que tutele sus derechos en el ámbito familiar. De esta manera, el Poder Jurídico colma entendimientos divergentes al tratar del derecho de custodia compartida de animal doméstico, ora por analogía, lo trata como sujeto de derecho, ora como impone la ley, en los termos del art. 82 del Código Civil, lo trata como simple objeto. Por lo tanto, mientras no hay la ley que dé a los animales no humanos um status que le confiera derechos, muy probable que no va a haber entendimiento pacificado en relación al derecho de custodia compartida de los animales domésticos.

Palabras clave: Mascotas; Sintiencia; Familia multiespecie; Derecho del animal; Custodia compartida de animales. 


\section{Introdução}

É crescente o pleito pela guarda compartilhada de animais domésticos no Brasil em ações judiciais que versam sobre a dissolução conjugal. O tema proposto se delimitará em abordar o status jurídico do animal não humano no ordenamento jurídico brasileiro, bem como sob a ótica da ciência demonstrar que os animais não humanos são sensitivos, capazes de integrar a família humana, denominada família multiespécie, ainda que a legislação brasileira os defina como objetos.

Primeiramente, para melhor compreensão e delimitação do tema, entende-se como animal doméstico aquele que sob o domínio do homem convive na mesma casa; ou também, nos termos do art.2 ${ }^{\circ}$, III da Portaria nº. 93/98 do IBAMA, todos os animais que através de processos de manejo ou melhoramento zootécnico tornam-se domésticos, desenvolvendo características biológicas e comportamentais em estreita dependência do homem, além da possível mudança de fenótipo variado tornando-os diferentes da espécie silvestre que se originou.

Avante, o ordenamento jurídico brasileiro atribui aos animais não humanos o status de coisa/objeto. A Constituição Federal, numa visão antropocêntrica, em seu art. $225, \S 1^{\circ}$, VII, veda os maus-tratos aos animais a fim puramente de proteger o animal enquanto propriedade e de garantir um ecossistema equilibrado para a saúde e bem-estar do homem. (Brasil, 1988).

Do mesmo modo, a legislação civilista os intitula, sem piedade, como bens móveis semoventes, nos termos do art. 82 do Código Civil (Brasil, 2002): "São móveis os bens suscetíveis de movimento próprio, ou de remoção por força alheia, sem alteração da substância ou da destinação econômico-social." As normas infraconstitucionais em sua maioria, também acompanham o mesmo entendimento.

Por outro lado, uma nova ordem social reconhece os animais não humanos como sensitivos (capazes de sentir), a ciência assim os declarou, e muito das famílias brasileiras assim os veem, inclusive os tratam como membros familiares, constituindo a família multiespécie, a qual é formada por animais não humanos e seus tutores, unidas pelo afeto.

O tema do presente estudo está direcionado ao direito do animal não humano; ao direito de família; bem como ao direito civil, tendo em vista que no momento da desconstituição da família multiespécie, por vezes acabam chegando até o Poder Judiciário pedidos de guarda compartilhada de animais domésticos. Porém, perante ausência de lei para tutelar esse direito, alguns Tribunais de Justiça por analogia aplicam os institutos de guarda previsto no direito de família, enquanto outros aplicam os institutos de posse e propriedade previstos no Código Civil.

A relevância do estudo se dá por demonstrar a dissonância do status jurídico do animal não humano sob a ótica antropocêntrica defronte ao conceito contemporâneo da família multiespécie, bem como a possibilidade da guarda compartilhada dos animais domésticos no divórcio ou dissolução da união estável; além ainda, da reflexão sobre o direito do animal não humano, e da necessidade de uma norma que os intitule como sujeito de direito.

\section{Metodologia}

A metodologia utilizada foi a de pesquisa bibliográfica em textos legais, doutrinas, artigos científicos imprescindíveis para busca de soluções do problema proposto pelo objeto de estudo. Foi aplicado o método teórico para o desenvolvimento das conclusões, as quais serão embasadas nas pesquisas realizadas com o fim de atender o objetivo geral do trabalho.

Primeiramente, foram selecionadas obras específicas sobre o tema, quais sejam: Vieira e Silva (2016). Animais Bioética e Direito. Ed. Zakarewicz, e Vieira, e Silva, (2020). Família Multiespécie Animais de Estimação e Direito. Ed. Zakarewicz.

A partir da leitura dessas obras, foi possível traçar a estrutura do presente estudo e buscar conhecimento em demais doutrinas, a fim de responder sobre a senciência dos animais não humanos e da possibilidade da constituição da família multiespécie. Nessa fase, tornou-se base para a pesquisa a Declaração de Curitiba de 2014 e a obra: Dias (2016). Manual de 
Direitos das Famílias.E-book. Revista dos Tribunais. Os artigos científicos sobrevieram como complementação para o alcance do objetivo.

Por seguinte, fez-se necessário a análise do tratamento dado ao animal não humano no ordenamento jurídico brasileiro, desde a Constituição Federal de 1988 às leis infraconstitucionais.

Por fim, a resposta do presente estudo se consolidou com pesquisas jurisprudenciais acerca do tema nos tribunais de justiça do Brasil.

\section{Status do Animal não Humano no Ordenamento Jurídico Brasileiro}

O animal não humano é tratado como objeto de direito desde a norma suprema às leis infraconstitucionais, sendo exceções as poucas leis estaduais que o trata como sujeito de direito, como disposto a seguir.

\subsection{Constituição Federal de 1988}

A Constituição Federal de 1988, nos termos do artigo 225, § 1º, VII, dispõe sobre o direito animal ao tratar do direito ao meio ambiente. A Carta Magna assegura a todos o direito de um meio ambiente ecologicamente equilibrado, sendo este, um bem de uso comum do povo e imprescindível à boa qualidade e saúde de vida.

Ademais, é direito e dever de todos defender e preservar o animal, tendo o Poder Público a obrigação de assegurar a efetividade da lei a fim de que a fauna e a flora sejam protegidas; vedadas, na forma da lei, condutas que coloquem em risco o sistema ecológico; acarretem em extinção de espécies; e a crueldade aos animais. In verbis:

Art. 225. Todos têm direito ao meio ambiente ecologicamente equilibrado, bem de uso comum do povo e essencial à sadia qualidade de vida, impondo-se ao Poder Público e à coletividade o dever de defendê-lo e preservá-lo para as presentes e futuras gerações.

$\S 1^{\circ}$ Para assegurar a efetividade desse direito, incumbe ao Poder Público:

VII - proteger a fauna e a flora, vedadas, na forma da lei, as práticas que coloquem em risco sua função ecológica, provoquem a extinção de espécies ou submetam os animais a crueldade. (grifo nosso).

Percebe-se que a proibição de maus-tratos aos animais está inteiramente ligada à proteção da fauna, relativamente à proteção do ecossistema. Trata-se de uma norma antropocêntrica, que diz respeito puramente ao interesse do homem.

Ao pensar que o ecossistema é bem de uso comum, que se equilibrado, propicia uma boa qualidade de vida ao povo, além de que, os maus-tratos aos animais e extinções de espécies prejudicariam o bem enquanto propriedade do homem e o sustento do homem enquanto alimentação.

Segundo Vieira e Silva (2016, p.13-14), em relação à norma constitucional supracitada, "vê-se claramente a filiação do ordenamento jurídico brasileiro à perspectiva antropocêntrica alargada.” Afirmam ainda que o ordenamento jurídico, ao conceder ao animal não humano o status de coisa, objeto, restringe-o tão somente à ordem econômica, considerando-o como propriedade do homem. Além do mais, caberia a Constituição Federal avançar, "alterando seu status jurídico de mero objeto, reconhecendoo de acordo com suas especialidades."

Enquanto o avanço constitucional não ocorre, as legislações infraconstitucionais na mesma perspectiva antropocêntrica, acompanham a norma suprema, como disposto a seguir.

\subsection{Lei Ambiental no 9.605/1998}

Em consonância com a Constituição Federal, o artigo 29 da Lei Ambiental nº. 9.605/1998, aduz que é crime contra a fauna "matar, perseguir, caçar, apanhar, utilizar espécimes da fauna silvestre, nativos ou em rota migratória" sem que haja 
permissão, autorização ou licença da autoridade competente para tal. A pena a quem infringir a norma é de detenção de (6) seis meses a um (1) ano, e multa.

Nessa toada, a mesma lei em seu artigo 32, penaliza com detenção, de 3 (três) meses a 1(um) ano, e multa, quem abusar, maltratar, ferir ou mutilar animais, sejam eles domésticos ou domesticados, silvestres, nativos ou exóticos.

Destaca-se que a Lei Sansão nº 14.064/2020, alterou o artigo supramencionado com a inclusão do parágrafo primeiro - A ( $\left(1^{\circ}-\mathrm{A}\right)$, o qual dita que se a conduta criminosa for contra cão e gato, a pena será de reclusão (regime fechado) de 2 (dois) até 5 (cinco) anos, cumulada de multa e proibição da guarda do animal. O texto legal acrescido na Lei Ambiental nº 9.605/1998, passou a viger nos seguintes termos:

Art. 32- Praticar ato de abuso, maus-tratos, ferir ou mutilar animais silvestres, domésticos ou domesticados, nativos ou exóticos:

Pena - detenção, de três meses a um ano, e multa.

(...)

$\underline{\S} 1^{\circ}$-A Quando se tratar de cão ou gato, a pena para as condutas descritas no caput deste artigo será de reclusão, de 2 (dois) a 5 (cinco) anos, multa e proibição da guarda._(grifo nosso).

Devido a essa alteração, os maus-tratos contra cão e gato deixaram de ser um crime de menor potencial ofensivo passando ao maior potencial ofensivo, penalizado com mais rigor, com reclusão, o que impossibilita a aplicação dos institutos despenalizadores da seara criminal, quais sejam: composição civil dos danos, transação penal, suspensão condicional do processo e o acordo de não persecução penal.

Diante disso, a breve análise da alteração legislativa comparada ao clamor da sociedade brasileira por um tratamento diferenciado aos animais, foi um bom avanço, porém pequeno, moldado por especismo e "preconceito", pois protegeu com maior rigor apenas o cão e o gato, e ignorou as demais espécies. ${ }^{1}$

\subsection{Código Civil 2002}

A esfera civilista, não diferente, calcada explicitamente pelo egoísmo antropocêntrico, nos termos do art. 82 do Código Civil, considera os animais como coisas, bens móveis e semoventes, suscetíveis de apropriação e comercialização pelo homem. Ipsis litteris: "São móveis os bens suscetíveis de movimento próprio, ou de remoção por força alheia, sem alteração da substância ou da destinação econômico-social.” (Brasil, 2002).

Nesse mesmo viés, pode-se dizer que a importância do animal está ligada ao valor econômico, sua regulação jurídica visa o benefício do homem; o animal é um objeto que serve o homem, seja no trabalho, no lazer ou na alimentação. À luz da legislação civil ele pode normalmente ser objeto de negócio jurídico, ou seja, pode ser vendido, doado, permutado, alienado, penhorado.

Nesse prisma, Milaré e Coimbra (2004), alegam que os animais não humanos, ainda que possuam alguns direitos, não têm obrigações e responsabilidades, tampouco capacidade de pleitear e exercer direitos por si próprios, devendo, portanto, serem considerados coisas, propriedade do homem.

De outro lado, Rodrigues (2012) apregoa que deveria ser concedido aos animais, a natureza jurídica sui generis, para que esses fossem tratados como sujeitos de direito.

\footnotetext{
${ }^{1} \mathrm{O}$ especismo é uma discriminação baseada na espécie; segundo esta visão, os interesses de um indivíduo têm menor importância pelo fato de este pertencer a uma espécie diferente da nossa. Richard Ryder cunhou o termo, originariamente "“'especiecismo"', ao constatar a proximidade deste com outros tipos de preconceito e discriminação, como o racismo e o machismo, por exemplo." (Silva,2009, p.52).
} 
Contudo, Vieira e Silva (2016) pontuam que, atualmente, há uma ordem social brasileira e mundial, divergente da legislação civilista, fundada na ciência que os vê como sencientes (sensitivos), capazes de sentir dor, angústia, solidão e prazer; seres capazes de pensar, dentro de suas particularidades.

A verdade é que a sociedade cada vez mais tem ignorado o status jurídico brasileiro dos animais não humanos tratandoos como se sensitivos fossem.

\section{A Senciência dos Animais}

Numa vertente divergente do ordenamento jurídico brasileiro, há a ciência afirmando que os animais não humanos são sencientes. Obviamente esses seres não podem ser tratados como coisas.

A denominação de senciência para Peter Singer (2002, p.420) está na "capacidade de sofrer ou sentir prazer ou felicidade."

Corrobora, Luna (2008, p.18) ao dizer que a senciência sinteticamente é a capacidade de sentir, de conhecer a si próprio ou do ambiente que o cerca.

Sob esse viés o III Congresso Brasileiro de Bioética e Bem-estar Animal, no ano de 2014, afirmou que os animais são sencientes, publicando a Declaração de Curitiba, nos seguintes termos: "Nós concluímos que os animais não humanos não são objetos. Eles são seres sencientes. Consequentemente, não devem ser tratados como coisas”. (Declaração de Curitiba, 2014, p.462-463).

A declaração supramencionada foi assinada por 25 especialistas do tema, dentre eles, cientistas renomados como Philip Low, Carla Forte Maiolino Molento, a médica veterinária, Luiza Schneider S. Castro, e o mestre em direito Daniel Braga Lourenço.

O Conselho Regional de Medicina do Mato Grosso do Sul, cita o neurocientista LOW, o qual afirma que não se trata de uma simples declaração, é teoricamente um contrato o qual os legisladores devem refletir sobre o seu teor. Nos seguintes termos: "Ela (a Declaração de Curitiba) é importante por ser o limite para quem faz as leis, que devem refletir sobre a forma como os animais devem ser tratados. Isso não é uma declaração de cientistas, é um contrato.” (CRMVMS, 2014, p.1).

Outrossim, o médico veterinário e professor, Stelio Pacca Loureiro Luna (2008, p.18), enfatiza que os animais não humanos sentem dor, tanto que tentam fugir quando percebem que irão sofrer, além disso, quando sentem dor e tomam analgésicos o sofrimento é melhorado. Nestes termos: "A evidência de que os animais sentem dor se confirma pelo fato que estes evitam ou tentar escapar de um estímulo doloroso e quando apresentam limitação de capacidade física pela presença de dor, esta é eliminada ou melhorada com o uso de analgésicos."

Observa-se que os ditames do ordenamento jurídico brasileiro ao tratar o animal não humano como objeto destoa do entendimento científico, o qual afirma a senciência dos animais não humanos.

Os autores, Vieira e Silva (2016, p.17), em exame da legislação vigente, afirmam que o dogma de coisas conferido aos animais deve ser extirpado e dado a eles o status jurídico de seres especiais, por meio de leis específicas de acordo com a particularidade de cada espécie, visando uma "efetiva e concreta proteção".

É inacreditável que o homem pense que o animal não humano seja incapaz de sentir. Bem provável que este entendimento equivocado seja resquícios do pensamento cartesiano (filosofia de René Descartes), o qual conceituou os animais não humanos como máquinas autônomas, incapazes de sentir dor.

No entanto, existem no Brasil algumas leis infraconstitucionais que vão ao encontro da ciência e reconhecem os animais não humanos como seres sencientes. 


\subsection{A senciência dos animais não humanos reconhecida pelas leis infraconstitucionais}

Destaca-se que algumas leis infraconstitucionais intitulam o animal não humano como um ser senciente, tais como: o Código Estadual de Proteção aos Animais de Santa Catarina, Lei nº. 12.854/2003, em seu artigo 34-A, reconhece cães e gatos como sencientes, sujeitos de direito; o Código Estadual do Meio Ambiente do Rio Grande do Sul, Lei n ${ }^{\circ}$. 15.434/2020, em seu artigo 216, de forma ampla, qualificou todos os animais domésticos de estimação como sujeitos de direito; a Lei do Estado de Minas Gerais que dispõe sobre os maus-tratos aos animais, Lei nº. 22.231/2016 alterada pela Lei $n^{\circ}$. 23.724/2020, em seu art. $1^{\circ}$, Parágrafo Único, que reconhece todos os animais como sencientes, sujeitos de direitos despersonificados; por fim, o Código de Direito e Bem-Estar Animal do Estado da Paraíba, Lei no. 11.140/2018, em seu artigo 5º sem qualquer especismo, reconheceu que todo animal tem o direito de ser respeitado, seja por questões físicas ou psíquicas; tem o direito a receber tratamento digno que possibilite uma vida saudável; um abrigo que o proteja das condições climáticas e os dê conforto; receber cuidados médicos; além do direito a um tempo de trabalho razoável, ao descanso adequado e a um repouso reparador. In verbis:

Art. $5^{\circ}$ Todo animal tem o direito:

I - de ter as suas existências física e psíquica respeitadas;

II - de receber tratamento digno e essencial à sadia qualidade de vida;

III - a um abrigo capaz de protegê-lo da chuva, do frio, do vento e do sol, com espaço suficiente para se deitar e se virar; IV - de receber cuidados veterinários em caso de doença, ferimento ou danos psíquicos experimentados;

V - a um limite razoável de tempo e intensidade de trabalho, a uma alimentação adequada e a um repouso reparador.

A lei paraibana, traduz a dignidade que todos os animais não humanos deveriam ter em direito.

Apregoam, Vieira e Silva (2016) que um dos efeitos de leis como estas, é de garantir que os animais, ao participar das relações familiares, sejam tratados como integrantes da família e não como meros objetos, bens patrimoniais de seus donos, tendo os animais o direito à guarda, às visitas e à pensão alimentícia.

Corrobora, Ataíde Junior (2020) ao indagar que nos Estados em que essas leis vigoram, provavelmente os animais não sejam objetos de partilha no momento do divórcio ou da dissolução da união estável, sendo considerados como sujeitos de direito. A verdade é que a sociedade brasileira cada vez mais tem contemplado o entendimento científico e tem tratado os animais não humanos como seres sensitivos, em especial, os domésticos, os quais, além de oferecer, recebem afeto e carinho de seus donos, ao ponto de serem considerados integrantes da família humana.

\section{Conceito de Família}

A Constituição Federal em seu artigo 226 reconhece a família como a união estável ou casamento entre homem e mulher, ou que seja formada por qualquer um dos pais e seus descendentes (Família Monoparental). Porém, o conceito que melhor se molda às novas estruturas de convívios e acompanha a evolução social, está previsto na Lei Maria da Penha, Lei ${ }^{\circ}$ 11.340/06, art. $5^{\circ}$, III, a qual coíbe a violência doméstica e familiar contra a mulher, e entende como entidade familiar qualquer relação intima de afeto.

Segundo Dias (2016), é imprescindível a visão de família pluralista abarcando diversos tipos de entidades familiares, constituídas e entrelaçadas pelo afeto, independente de quem as compõem. É preciso observar o vínculo afetivo que une seus integrantes à entidade familiar.

Consoante a isso, Braga, apresenta o modelo de família potestativa, na qual se tem o direito e liberdade de formar a família, assim como melhor entender, unidas pela aproximação existencial do afeto. (Dias, 2016, apud Braga, 2016).

É sob esse prisma contemporâneo que a doutrina inclina para vários modelos de famílias, tais como as poliafetivas, monogâmicas, virtuais e multiespécies, esta última que é constituída pelos animais de estimação e seus donos, modelo familiar abordado no presente estudo. 
Aliás, os animais não humanos domésticos no âmbito das relações familiares podem vir a ser considerados sujeitos de direitos e não meros objetos?

A ciência, como dito anteriormente, considera o animal não humano como senciente, logo, é capaz de transmitir afeto e carinho aos seus donos. Se a recíproca é verdadeira, embasados no conceito contemporâneo de família, estamos, sim, diante de uma família multiespécie, a qual intitula seu animal de estimação como um de seus membros familiar.

Concluído isto, é possível a reflexão de que na dissolução conjugal dessas famílias o animal será tratado como sujeito de direito e não como mero objeto.

\subsection{Da aplicação da norma por analogia}

Ainda que a legislação Brasileira seja feita pelo homem para o homem, as mudanças sociais contribuem para a evolução do direito, e o novo conceito de família, a multiespécie, ultimamente tem provocado o Poder Judiciário a se manifestar sobre questões envolvendo alimentos, direito de visitas e guarda de animais domésticos em ações de divórcio ou dissolução da união estável.

Como não há lei específica que discipline o direito dos animais, por analogia, aplica-se a legislação dos homens para a resolução das lides. Não é devido ausência de lei que esses genuínos ficarão desamparados.

Nessa baila, Valle e Borges (2018) afirmam que o Código Civil não disciplina os cuidados essenciais e os direitos de convivência dos animais com seus donos, portanto os operadores do direito devem se utilizar da analogia para a resolução dos conflitos.

Para Cardin e Vieira, a analogia é como uma ferramenta para superar a omissão legislativa no que tange o direito do animal. Seria a solução de pleitos judiciais se o preenchimento desta lacuna se desse com a aplicação do direito de guarda da criança e do adolescente, bem como dos demais direitos do âmbito familiar em casos da dissolução conjugal. (Tobbin, 2020, apud Cardin \& vieira 2017).

Nesse sentido, o Relator José Rubens Queiroz Gomes, do Tribunal de Justiça do Estado de São Paulo, em julgamento de Apelação Cível n. ${ }^{\circ} 1003813$ 20.2020.8.26.0001, em seu voto ( $n^{\circ}$ 20543) salientou que os animais de estimação não podem ser tratados como bens, visto que cada vez mais estes seres são considerados como membros familiar, motivo o bastante para aplicação por analogia do instituto de guarda previsto no Código Civil para solucionar a lide. Vê-se:

Não há em nosso ordenamento jurídico uma norma ou lei específica acerca da 'partilha' de animais de estimação, os quais, todavia, não podem continuar a ser tratados como "bens" porquanto cada vez mais são considerados como membros da família. Dessa forma, tem-se entendido possível, em casos como o presente, aplicar-se por analogia as regras estipuladas para a guarda de filhos. (Apelação Cível no 1003813-20.2020.8.26.0001 -Voto n. ${ }^{\circ} 20543$ - A 3).

Dito isso, o relator por analogia aplicou o artigo 1.584 do Código Civil, e manteve a sentença de $1^{\circ}$ grau, a qual deferiu a guarda do animal à sua tutora. In verbis:

APELAÇÃO. AÇÃO DE DIVÓRCIO. SENTENÇA DE PROCEDÊNCIA. PRETENSÃO DE GUARDA COMPẢRILHẢDA, RATEANDO-SE AS DESPESAS COM ALIMENTAÇÃO E SAÚDE. DECISÃO MANTIDA. Aplicação do disposto na última parte do artigo $\mathbf{1 . 5 8 4}$ do $\mathbf{C C}$, por analogia. Guarda mantida nos termos estabelecidos na r. sentença, com a observação, contudo, acerca da possibilidade de requerer o apelante, em via autônoma, a regulamentação de visitas quanto ao cão que não ficou sob sua guarda, diante do evidente vínculo afetivo, embora não seja possível enfrentamento da questão por ausência de pedido expresso. Recurso a que se nega provimento, com observação. (TJ-SP - AC: 10038132020208260001 SP 1003813-20.2020.8.26.0001, Relator: José Rubens Queiroz Gomes, Data de Julgamento: 03/05/2021, 7ª Câmara de Direito Privado, Data de Publicação: 03/05/2021). (grifo nosso). 
Diante do que pensam os autores e entendimento jurisprudencial, conclui-se que a analogia pode ser utilizada a fim de preencher a lacuna legislativa ao tratar da guarda de animais no momento da dissolução conjugal.

\section{Da Possibilidade da Disputa da Guarda dos Animais Domésticos em Sede de Dissolução Conjugal.}

Atualmente, a maioria dos lares brasileiros possuem um animal de estimação, pois a pesquisa do IBGE do ano de 2019, apontou que 47,9 milhões de domicílios no Brasil abrigam ao menos um cão ou gato. Muitos deles são membros de uma família multiespécie, que ao ser desconstituída, por vezes são envolvidos em disputas judiciais entre os cônjuges ou companheiros requerendo a sua guarda.

É comum pais pleitearem na mesma ação de divórcio ou dissolução da união estável, a guarda dos filhos; momento que frequentemente há discussões, pois nem sempre os pais entram num consenso e a lide acaba sendo resolvida pelo Magistrado, o qual observará o caso concreto visando o melhor interesse do infante. O ideal seria a mesma observação ao tratar do direito de guarda do animal.

Vieira e Silva (2020), aponta que a tendência de reconhecer os animais como seres sencientes e integrantes da entidade familiar, ao fim da convivência conjugal, a justiça tem reconhecido a cotitularidade destes, ao estabelecer a custódia compartilhada e pagamento de alimentos.

No mesmo sentido, o Enunciado nº 11 do Instituto Brasileiro de Direito de Família, em sede de dissolução conjugal, indica a guarda compartilhada do animal, como direito do animal, nos seguintes termos: "Na ação destinada a dissolver o casamento ou a união estável, pode o juiz disciplinar a custódia compartilhada do animal de estimação do casal. ” (IBDEFAM, 2015, p. 1).

Compreendido a possibilidade da disputa de guarda de animais domésticos na dissolução conjugal, explicar-se-á as duas modalidades de guarda previstas no ordenamento jurídico brasileiro, sendo elas: A guarda Unilateral e a Compartilhada, as quais poderão tutelar os direitos desses pequenos sencientes. Portanto, para melhor compreensão, especificamente no contexto temático do presente estudo presume-se que toda vez que a legislação se referir ao filho menor quanto aos direitos de guarda, compreende-se como sendo o animal de estimação, membro da família multiespécie.

Nos termos do artigo 1.583, $\S 1^{\circ}$, do Código Civil, "a guarda será unilateral ou compartilhada", sendo a unilateral aquela atribuída somente a um dos seus genitores, ou para alguém que o substitua e a compartilhada é "a responsabilização conjunta e o exercício de direitos e deveres do pai e da mãe que não vivam sob o mesmo teto, concernentes ao poder familiar dos filhos comuns." (Brasil, 2002).

A modalidade mais aplicada nas resoluções dos litígios é a compartilhada, vista como uma forma de resguardar o direito de convívio harmônico entre os pais, facilitar o exercício do poder familiar além de favorecer o bom e saudável desenvolvimento do menor. Dessa forma, os reflexos da separação mudando a vida do menor serão mais brandos.

Entretanto, não se olvide que o tempo de convívio entre filho e os guardiões será de acordo com as condições fáticas embasada no princípio do melhor interesse do menor, nos termos do $1.583, \S 2^{\circ}$ Código Civil.

Outrossim, a guarda unilateral ou compartilhada, nos termos do artigo 1.584, do Código Civil, poderá ser requerida de forma consensual, pelos pais, ou por qualquer um deles, em sede de divórcio, dissolução de união estável ou em medida cautelar e "é decretada pelo Juiz, em atenção a necessidades específicas do filho, ou em razão da distribuição de tempo necessário ao convício deste com o pai e com a mãe.” (Brasil, 2002).

Destaca-se que o art. 1584, $\S 2$-do Código Civil, aduz que não havendo acordo entre os pais quanto a guarda do filho, se ambos estiverem aptos a exercer o poder familiar, será aplicada a guarda compartilhada, salvo se um deles declarar ao Juízo que não a deseja. 
Destarte, a Lei da Alienação Parental nº.12.318/10 em seus artigos $6^{\circ}$, v, e $7^{\circ}$ dão prioridade à guarda compartilhada; e o Estatuto da Criança e do Adolescente - ECA em seu art. 42, $\S 5^{\circ}$, assegura a guarda compartilhada em casos de adoção, mesmo que os candidatos a adoção sejam separados ou divorciados.

É perceptível que a legislação se inclina em manter o menor mais próximo possível da vida que levara antes da separação dos pais, afinal a relação dissolvida é a conjugal e não a relação parental.

De mais a mais, Maria Berenice Dias, afirma que a guarda compartilhada traz benesses a todos, visto que nessa modalidade os pais têm a possibilidade de participar de forma mais intensa na vida dos filhos, além pluralizar as responsabilidades, ocorrendo então, uma democratização de sentimentos. (Conteúdo Jurídico, 2008, p.1)

De todo exposto, sem dúvidas, a manutenção do convívio dos filhos com os pais, favorece o bom desenvolvimento da criança/adolescente, fazendo com que as mudanças sejam menos drásticas no estilo de vida que já possuíam. Além de que, a guarda compartilhada divide as obrigações e responsabilidades dos pais para com os filhos, simplificando a lida de ambos nesse processo.

\section{Das Benesses da Guarda Compartilhada de Animais Domésticos}

A palavra guarda no Dicionário Online de Português significa proteção, vigilância, cuidado; e a palavra compartilhada é o mesmo que fazer parte de algo com alguém, dividir. No âmbito das relações familiares a guarda compartilhada diz respeito ao dever dos pais em proteger e cuidar dos filhos de forma compartilhada para que eles tenham um pleno desenvolvimento até atingir a maioridade.

Como já demonstrado, os animais da família multiespécie não podem ficar desamparados devido a separação de seus tutores. Por conta disto, o Magistrado, na tomada de decisão deverá observar o caso concreto e avaliar o bem-estar do animal.

A reflexão que se deve fazer é de que se o animal não humano é senciente, membro familiar, o seu tratamento deve ser equiparado ao tratamento dado ao menor quando discutida a guarda. Seria a humanização dos animais? Não, os animais não são humanos, mas também não são objetos como já provado cientificamente e conferido pela família multiespécie. Como não há legislação que os tratem adequadamente, nada mais justo que tratá-los aplicando a legislação feita direcionada aos homens, um ser que sente tanto quanto os animais.

Nesse sentido, pontua Maria Berenice Dias (2008) que, “a dissolução dos vínculos afetivos não leva à cisão quanto aos direitos nem quanto aos deveres com relação aos filhos" e esta ruptura não deve "comprometer a continuidade dos vínculos parentais, pois o exercício do poder familiar em nada é afetado pela separação.” É necessário manter os laços de afetividade, minorando os efeitos que a separação acarreta aos filhos”. (Conteúdo Jurídico, 2008, p.1).

Ademais, sabendo que os impactos da separação podem trazer mudanças de comportamentos, deixando-os tristes, quietos ou até mesmo perturbados e agressivos, a decisão mais assertiva dos tutores na dissolução conjugal, pensando no bemestar animal, seria o pleito pela guarda compartilhada, a fim de manter a convivência com seu animal de estimação, além da divisão de responsabilidades e obrigações entre seus tutores.

Nesse contexto, Ana Carolina Leonardi, ao falar sobre o sofrimento dos animais com a separação, citou, Angie Johonsn, cientista pesquisadora da cognição canina, a qual afima que a dissolução conjugal traz mudanças no ambiente, muda o cheiro, as roupas e os objetos de um dos tutores somem, fatores usados como ponto de referência pelo animal; isso tudo pode deixá-lo inseguro, triste e solitário.

Para Johonsn, a perspectiva que se tem é bastante humana, porém a tendência é de que seja mais complexa ainda, pois enquanto o casal sabe os motivos pelos quais romperam o vínculo conjugal e tem a certeza dessa cisão, o animal não tem noção do caráter definitivo disso, ele percebe que um de seus tutores está ausente, porém sempre esperará pelo seu retorno. 
É de extrema importância que sejam mantidos os laços afetivos do animal com seus tutores, ainda que o animal necessite que alguém arque com suas despesas para sobrevivência, o amor e o carinho devem prevalecer. Por isso, nem sempre quem tem mais poder aquisitivo consegue oferecer o melhor para o animal; dispor de tempo e atenção para com seu "animal filho", questões que devem ser pontuadas pelo Magistrado no deferimento da guarda.

Nesse sentido, Tobbin e Cardin (2020) afirmam que nem sempre a parte que possui melhores condições financeiras é a pessoa mais apta a oferecer ao animal melhor bem-estar. Ainda que o animal possua gastos com alimentação, higiene, saúde, espaço ideal para o seu desenvolvimento, os laços afetivos têm maior relevância em comparação ao poder econômico, nem sempre o adotante ou comprador do animal tem mais convivência e maior afetividade para com ele.

Para Cardin e Vieira, considerar o melhor interesse do animal é cumprir o mandamento constitucional previsto no artigo 225, §, VII da CF/1988 o qual veda os maus-tratos aos animais. E que devido à ausência de lei que tutela a guarda de animais, é possível aplicar as regras previstas no artigo 33 do Estatuto da Criança e do Adolescente, devido a vulnerabilidade do animal e a sua dependência com os tutores. Sendo assim, os animais devem sim ser tratados como "membro não humano", porém, sujeitos de direitos da família multiespécie. (Tobbin \& Cardin, 2020 apud Cardin \& vieira, 2017).

Contudo, na maioria das vezes que se disputa a guarda do animal via judicial, a lide é resolvida como sendo o animal propriedade ou posse do homem, quando na verdade deveria ser tradado como sujeito de direito.

\section{Das Decisões Judiciais Quanto a Guarda Compartilhada de Animais Domésticos}

Ante a ausência de lei que tutele o direito do animal não humano os tribunais de justiça cumulam entendimentos diversos ao tratar da guarda compartilhada de animais domésticos, ora compreendem o animal como objeto, propriedade do homem; ora como sencientes, sujeito de direito.

Tobbin e Cardin (2020) traz como a exemplo o Tribunal de Justiça do Estado do Rio de Janeiro- TJ/RJ que ao julgar a apelação nº 00019757-79.2013.8.19.0208, deferiu a posse parcial do cão de estimação à ex-convivente envolvida em discussão de partilha de bens.

O Magistrado fundamentou-se na questão de que o animal não pode ser tratado como objeto/bem, e sem reflexão alguma ser partilhado e romper os vínculos emocionais e afetivos de forma abrupta. Porém, acabou deferindo a posse do cão à exconvivente, não pensando no melhor interesse do animal, mas na primazia do princípio da dignidade da pessoa humana em face da ex-convivente (recorrente), que sofreria com a perda do convívio com o animal.

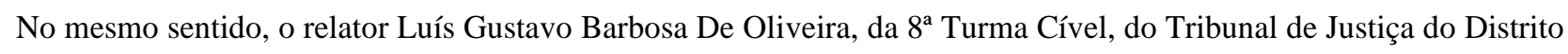
Federal, ao julgar o Agravo de Instrumento $\mathrm{n}^{\mathrm{o}}$. 0050135-88.2016.8.07.0000, interposto a fim do reconhecimento da guarda compartilhada, firmou em sua decisão que é descabido a aplicação do direito de família ao requerer a guarda, visto que os animais são, semoventes, coisas, no âmbito Civil. Enfatizou o relator:

Inexiste plausibilidade jurídica no pedido de aplicação do instituto de família, mais especificamente a guarda compartilhada, aos animais de estimação, quando os consortes não têm consenso a quem caberá a posse dos bichos. Tratando-se de semoventes, são tratados como coisas pelo Código Civil e como tal devem ser compartilhados, caso reste configurado que foram adquiridos com esforço comum e no curso do casamento ou da entidade familiar (artigo 1.725, CC). (DJE, 2017, p. 491-501). (grifo nosso).

Na mesma baila, o Tribunal de Justiça do Estado de São Paulo, manteve a fixação da guarda compartilhada dos animais de estimação ao julgar o Agravo de Instrumento $n^{\circ}$. 22815174820198260000, atendendo unicamente aos interesses dos excônjuges denominados proprietários. Nos termos: 
DIVÓRCIO - PEDIDO DE TUTELA PROVISÓRIA VISANDO À FIXAÇÃO DA GUARDA COMPARTILHADA DOS ANIMAIS DE ESTIMAÇÃO DO CASAL - INDEFERIMENTO - DECISÃO MANTIDA - Compartilhamento da posse dos animais que exige o consenso comum e deve atender aos interesses de ambos os proprietários Imprescindibilidade, ao menos, do aguardo da formação do contraditório nos autos - Recurso desprovido. (TJ-SP - AI: 22815174820198260000 SP 2281517-48.2019.8.26.0000, Relator: Galdino Toledo Júnior, Data de Julgamento: 28/01/2020, $9^{a}$ Câmara de Direito Privado, Data de Publicação: 28/01/2020).(grifo nosso).

Em outro vértice, a $4^{a}$ Turma do Supremo Tribunal de Justiça, em sede do Recurso Especial no $\mathrm{n}^{\circ} 1713167$ SP 2017/0239804-9 (2018), em que o pleito era o direito de visita ao animal, externou o entendimento sobre várias peculiaridades tratados pelo presente estudo, inclusive sobre a guarda.

O STJ no caso supracitado, entendeu que, a manutenção da relação de afeto ao animal é cumprir o Mandamento Constitucional; ainda que o Código Civil trate os animais como coisas não se pode negar que eles possuem um valor subjetivo, especial e íntimo entre seus donos. Os animais possuem natureza especial, são sencientes, não são posses e tampouco propriedades; contudo não se pode aplicar o instituto da guarda do direito de família por se tratar de um ônus exercido no interesse tanto dos pais quanto dos filhos; porém, não deve ser desprezado o vínculo de afeto dos cônjuges pelo animal, além da observação do bem-estar animal.

Vale destaque os argumentos colacionados pelo Relator e Ministro Luís Felipe Salomão, ao apreciar o referido recurso.

O relator indagou em seu voto que, preliminarmente, deve ser extirpado a ideia da impossibilidade de discutir o direito do animal no âmbito familiar, ou até mesmo do pensamento de que a causa é menor ou fútil. Visto que é recorrente discussões acerta da afetividade dos animais e seus tutores, além ainda, do dever de cumprir o que dita a Constituição Federal, proteger o meio ambiente. Ipsis litteris:

Inicialmente, deve ser afastada qualquer alegação de que a discussão envolvendo a entidade familiar e o seu animal de estimação é menor, ou se trata de mera futilidade a ocupar o tempo desta Corte. Ao contrário, é cada vez mais recorrente no mundo da pós-modernidade e envolve questão bastante delicada, examinada tanto pelo ângulo da afetividade em relação ao animal, como também pela necessidade de sua preservação como mandamento constitucional (art. 225, § 1, inciso VII -"proteger a fauna e a flora, vedadas, na forma da lei, as práticas que coloquem em risco sua função ecológica, provoquem a extinção de espécies ou submetam os animais a crueldade.

Destarte, prosseguiu o relator afirmando que ainda que o Código Civil tenha tipificado os animais como coisas, objetos de direito, sem personalidade jurídica, o fato destes seres receberem afeto no âmbito familiar, não altera sua natureza jurídica. Porém, não se pode negar que os animais domésticos possuem um valor subjetivo e peculiar, sendo possível uma estreita relação íntima de afeto com seus tutores, não se vislumbra isso com qualquer outro tipo de propriedade privada. Vejam:

Na forma da lei civil, o só fato de o animal ser tido como de estimação, recebendo o afeto da entidade familiar, não pode vir a alterar sua substância, a ponto de converter a sua natureza jurídica. No entanto, os animais de companhia possuem valor subjetivo único e peculiar, aflorando sentimentos bastante íntimos em seus donos, totalmente diversos de qualquer outro tipo de propriedade privada. Dessarte, o regramento jurídico dos bens não se vem mostrando suficiente para resolver, de forma satisfatória, a disputa familiar envolvendo os pets, visto que não se trata de simples discussão atinente à posse e à propriedade.

Avante, o relator indagou que não se pode aplicar o instituto da guarda para decidir o futuro dos animais, pois a guarda é um direito imposto, inerente do poder familiar. Nos termos: "múnus exercido no interesse tanto dos pais quanto do filho, não se trata de uma faculdade, e sim de um direito, em que se impõe aos pais a observância dos deveres inerentes ao poder familiar." Contudo, nos tempos em que vivemos, pós-modernidade, não se pode ignorar o relevo da relação do homem e seu animal de estimação. O que, inclusive, justifica a disputa dentro da entidade familiar onde prepondera o afeto dos cônjuges pelo animal. 
Em seguida o relator afirmou a senciência dos animais, os quais sofrem das mesmas dores e necessidades biopsicológicas dos homens. Nos seguintes termos: “Os animais de companhia são seres que, inevitavelmente, possuem natureza especial e, como ser senciente - dotados de sensibilidade, sentindo as mesmas dores e necessidades biopsicológicas dos animais racionais -, também devem ter o seu bem-estar considerado".

Por fim, enfatizou que em casos de conflitos no âmbito familiar envolvendo o animal de estimação, independentemente de seu status jurídico, deve ser observado o caso concreto perante a própria evolução da sociedade a fim de proteger o ser humano e o próprio vínculo afetivo com o animal.

Consoante a isso, decidiu a $4^{\text {a }}$ Turma do STJ, ao direito de visitas no neste caso, pois foi constatado relação de afeto entre o recorrente e o seu animal de estimação. Vê-se:

RECURSO ESPECIAL. DIREITO CIVIL. DISSOLUÇÃO DE UNIÃO ESTÁVEL. ANIMAL DE ESTIMAÇÃO. AQUISIÇÃO NA CONSTÂNCIA DO RELACIONAMENTO. INTENSO AFETO DOS COMPANHEIROS PELO ANIMAL. DIREITO DE VISITAS. POSSIBILIDADE, A DEPENDER DO CASO CONCRETO. (...) Na hipótese, o Tribunal de origem reconheceu que a cadela fora adquirida na constância da união estável e que estaria demonstrada a relação de afeto entre o recorrente e o animal de estimação, reconhecendo o seu direito de visitas ao animal, o que deve ser mantido. 9. Recurso especial não provido. (STJ - REsp: 1713167 SP 2017/0239804-9, Relator: Ministro LUIS FELIPE SALOMÃO, Data de Julgamento: 19/06/2018, T4 - QUARTA TURMA, Data de Publicação: DJe 09/10/2018). (grifo nosso).

Acompanha o mesmo entendimento a $10^{\mathrm{a}}$ Câmara de Direito Privado, do Tribunal de Justiça do Estado de São Paulo, que deferiu o Agravo de Instrumento, aduzindo a possibilidade de regulamentação de guarda de animais de estimação por se tratar de seres sencientes, nos termos:

AGRAVO DE INSTRUMENTO. GUARDA DE ANIMAIS DE ESTIMAÇÃO. DECISÃO QUE REVOGOU A COMPARTILHADA LIMINARMENTE DEFERIDA. RECURSO PROVIDO. Possibilidade de regulamentação da guarda de animais de estimação, seres sencientes, conforme jurisprudência desta C. Câmara e deste E. Tribunal. (...) Decisão reformada. Recurso provido. (TJ-SP - AI: 22074432320198260000 SP 2207443-23.2019.8.26.0000, Relator: J.B. Paula Lima, Data de Julgamento: 05/11/2019, $10^{\text {a }}$ Câmara de Direito Privado, Data de Publicação: 29/01/2020).

Corrobora o Relator Sulaiman Miguel, do Tribunal de Justiça do Estado de São Paulo, em decisão monocrática sobre conflito de competência para julgamento de guarda de animais, o qual dispôs sobre a relevância do valor subjetivo do animal no contexto familiar. In verbis:

CONFLITO NEGATIVO DE COMPETÊNCIA. AÇÃO DE GUARDA COMPARTILHADA DE ANIMAL DOMÉSTICO. REDISTRIBUIÇÃO AO JUÍZO SUSCITANTE SOB A ALEGAÇÃO DE CONEXÃO COM A AÇÃO DE DIVÓRCIO. CABIMENTO. A despeito da natureza jurídica conferida aos animais pelo Código Civil, não há como desconsiderar o valor subjetivo envolvido no contexto familiar. Divergência quanto ao vínculo afetivo entre o animal doméstico e seus donos a ser apreciado pela Vara da Família em caso de divórcio. Inteligência do Enunciado $\mathrm{n}^{\circ} 11$ do IBDFAM. Aplicação, por analogia, dos arts. 1.583 a 1.590, do CC. Precedentes. CONFLITO PROCEDENTE. COMPETÊNCIA DO JUÍZO SUSCITANTE. (TJ-SP - CC: 00243730320208260000 SP 0024373-03.2020.8.26.0000, Relator: Sulaiman Miguel, Data de Julgamento: 24/08/2020, Câmara Especial, Data de Publicação: 24/08/2020).(grifo nosso).

Diante de todo o exposto, denota-se que enquanto não existir uma lei específica que dê ao animal não humano o status a ele merecido e tão clamado pela sociedade brasileira, haverá divergências de entendimentos no Poder Judiciário em relação ao direito do animal. 


\section{Considerações Finais}

Do presente estudo, conclui-se que o ordenamento jurídico brasileiro necessita avançar em relação ao Direito do animal não humano, visto que estes, legalmente são tratados como coisas, quando na verdade a ciência e a sociedade os têm como sencientes.

Observa-se que a Constituição Federal e as Leis Infraconstitucionais, foram feitas pelo homem para o homem. Quando a norma veda os maus-tratos aos animais o objetivo é de proteger a fauna e a flora, consequentemente o meio ambiente que é um direito do homem não será prejudicado. Há algumas Leis Estaduais que reconhecem os animais não humanos como sencientes, porém, comumente protegem apenas cães e gatos. As leis que conferem a senciência a todos os animais, por enquanto, são as exceções, como a exemplo o Código de Direito e Bem-estar animal do Estado da Paraíba, Lei 11.140/2018 a Lei nº 22.231/2016 alterada pela lei n $n^{\circ} 23.724 / 2020$ do Estado de Minas Gerais.

Denota-se que a cultura e os fatos sociais contribuem para a evolução do Direito, o que justifica o conceito de família multiespécie, visto que segundo o IBGE os lares brasileiros possuem mais cães e gatos que crianças, e muitos destes, são considerados membros familiares, sencientes, capazes de terem uma relação de afeto com seus tutores.

Contudo, ainda que a ciência tenha declarado a senciência dos animais não humanos e a sociedade brasileira assim os tratem, inexiste lei para tutelar os direitos dos animais não humanos no âmbito familiar. Motivo pelo qual o Poder Judiciário cumula entendimentos divergentes ao tratar do direito de guarda compartilhada do animal doméstico em sede de dissolução conjugal. Ora aplica-se o Código Civil conferindo a eles o status de coisas, objetos de direito; ora por analogia, os intitulam de sencientes, sujeitos direito; ora visam o bem estar dos proprietários; ora visam o bem estar do animal; ora falam de posse; ora falam de guarda.

Portanto, o que se espera é que o ordenamento jurídico brasileiro evolua compreendendo as mudanças sociais; bem como o conceito de família multiespécie; a declaração da ciência, e atribua aos animais não humanos um status que lhe confira direitos. Tão somente assim, o Poder Judiciário pacificará um entendimento no que diz respeito à guarda compartilhada de animais domésticos e os demais direitos no âmbito familiar.

Diante de todo exposto, é possível vislumbrar futuras pesquisas sobre positivação do direito animal, bem como direito às visitas e alimentos. Além é claro, da possibilidade de alteração do status jurídico do animal não humano como sujeito de direito.

\section{Agradecimentos}

Em especial ao professor e orientador Eduardo Maffei, o qual colaborou intensivamente nesse processo de aprendizagem e apoiou a publicação desse artigo.

\section{Referências}

Ataíde, J. V. P. (2020). As Famílias Multiespécies à Luz dos princípios do direito animal. In: Vieira, T. R., Silva, C. H. Família Multiespécie Animais de Estimação e Direito. Ed. Zakarewicz. p.13-42.

Brasil. (2002) Código Civil. Lei $N^{o}$ 10.406, de 10 de janeiro de 2002. http://www.planalto.gov.br/ccivil_03/leis/2002/L10406compilada.htm.

Brasil. (1988). Constituição Da República Federativa Do Brasil De 1988. http://www.planalto.gov.br/ccivil_03/constituicao/constituicao.htm.

Brasil. (1998). Lei Ambiental n. ${ }^{\circ} 9.605$, de 12 de Fevereiro de 1998. http://www.planalto.gov.br/ccivil_03/leis/19605.htm.

Brasil. (2020). Lei $n^{\circ} 23.724$, de 18 de dezembro de 2020. https://www.legisweb.com.br/legislacao/?id=406385.

Brasil. (2020). Lei Sansão n. ${ }^{\circ}$ 14.064, de 29 de Setembro de 2020. .http://www.planalto.gov.br/ccivil_03/leis/19605.htm.

Brasil. (2019) Tribunal de Justiça do Estado de São Paulo (10 ${ }^{\mathrm{a}}$ Câmara). Agravo de Instrumento $n^{o}$. 2207443-23.2019.8.26.0000.https://tjsp.jusbrasil.com.br/jurisprudencia/894456431/agravo-de-instrumento-ai-22074432320198260000-sp-2207443-2320198260000. 
Brasil. (2020). Tribunal de Justiça do Estado de São Paulo. Agravo de Instrumento $n^{o}$. $22815174820198260000 . \quad$ https://tjsp.jusbrasil.com.br/jurisprudencia/803157675/agravo-de-instrumento-ai-22815174820198260000-sp-2281517-4820198260000/inteiro-teor-803157696.

Congresso Brasileiro de Bioética e Bem-estar animal. (2014). Declaração de Curitiba. http://www.labea.ufpr.br/portal/wp-content/uploads/2014/09/Anais-IIICBBBEA.pdf.

Conselho Regional De Medicina Do Estado Do Mato Grosso Do Sul - CRMVMS. (2014). Congresso resulta em Declaração de Curitiba que afirma que os animais não podem ser tratados como coisas. http://www.crmvms.org.br/noticia/congresso-resulta-em-declaracao-de-curitiba-que-afirma-que-os-animais-naopodem-ser-tratados-como-coisas.

Oliveira, L. G. B. (2017). Tribunal de Justiça do Distrito Federal e Territórios TJ-DF. (8 $8^{\text {a }}$ Turma) Agravo de Instrumento n ${ }^{o}$. 0050135-88.2016.8.07.0000. https://tj-df.jusbrasil.com.br/jurisprudencia/457779090/20160020474570-0050135-8820168070000.

Dias, M. B.(2008). Guarda compartilhada, uma novidade bem-vinda! Conteúdo Jurídico.com.br. http://www.conteudojuridico.com.br/consulta/Artigos/15 066/guarda-compartilhada-uma-novidade-muito-bem-vinda\#: :text=Guarda\%20Compartilhada\%2C\%20uma\%20novidade\%20muito\%20bem\%20vinda!,-

Direito\%20Civil\&text=Historicamente\%20os\%20filhos\%20ficavam\%20sob,desempenhar\%20as\%20fun\%C3\%A7\%C3\%B5es\%20de\%20maternagem.\&text= N\%C3\%A3o\%20mais\%20se\%20limita\%20o,do\%20outro\%20(CC\%201.589).

Dias. M. B.(2016). Manual de Direitos das Famílias. Maria Berenice Dias. (4a ed.), Revista dos Tribunais.

Dicio.com.br. Dicionário Online De Português. https://www.dicio.com.br/guarda/.

Gomes, J. R. Q.(2021). Tribunal de Justiça de São Paulo. (7a Câmara de Direito). Apelação $n^{o}$ 10038132020208260001. Voto N ${ }^{o} .20543$. https://tjsp.jusbrasil.com.br/jurisprudencia/1202683047/apelacao-civel-ac-10038132020208260001-sp-1003813-2020208260001/inteiro-teor-1202683068.

Instituto Brasileiro de Direito de Família - IBDFAM. (2015). Enunciado $N^{o}$.11. IBDFAM. https://www.ibdfam.org.br/conheca-o-ibdfam/enunciados-ibdfam.

Instituto Brasileiro de Geografia e Estatística-IBGE. (2019) Informações sobre domicílios, acesso e utilização dos serviços de saúde. Pesquisa Nacional de Saúde, 2019. https://biblioteca.ibge.gov.br/visualizacao/livros/liv101748.pdf.

Instituto Brasileiro do Meio Ambiente e dos Recursos Naturais Renováveis (1998). Portaria nº.93/98. http://www.ibama.gov.br/sophia/cnia/legisla cao/IBAMA/PT0093-070798.PDF.

Leonard, A. C. (2017). É verdade que cachorros sofrem quando os donos se separam? Exame.com. 2017, apud Johonsn, Angie. htps://exame.com/casual/e-verdade-que-cachorros-sofiemquando-os-donos-se-separam.

Luna, S. P. L (2008). Dor, Senciência E Bem-Estar Em Animais. Ciênc. vet. tróp. 11, 17-21. http://rcvt.org.br/suplemento11/17-21.pdf.

Miguel, S.(2020). Tribunal de Justiça do Estado de São Paulo. Câmara Especial. Conflito de Competência. Sucitação de Conflito de Competência $n^{o}$. 00243730320208260000. Voto $n^{o}$. 09505. https://tj-sp.jusbrasil.com.br/jurisprudencia/1119995651/conflito-de-competencia-civel-cc-243730320208260000sp-0024373-0320208260000/inteiro-teor-1119995703.

Miralé, É. \& Coimbra, J. D. Á. A.(2004). Antropocentrismo x Ecocentrismo na ciência jurídica. Revista de Direito Ambiental. 9, 9-41,

Paraíba, (Estado). (2018). Código de Direito e Bem-estar animal do Estado da Paraíba, Lei $n^{\circ} .11 .140$, de 08 de junho de 2018. https://www.legisweb.com.br/legislacao/?id=361016.

Rio grande do sul (Estado). (2020). Código Estadual do Meio Ambiente do Estado do Rio Grande do Sul. Lei $n^{o}$ 15.434, de 9 de Janeiro de 2020. https://leisestaduais.com.br/rs/lei-ordinaria-n-15434-2020-rio-grande-do-sul-institui-o-codigo-estadual-do-meio-ambiente-do-estado-do-rio-grande-do-sul.

Rodrigues, D. T.(2012). O Direito \& Os Animais: Uma abordagem ética, filosófica e normativa. (2a ed.), Juruá.

Salomão, L. F.(2018). Supremo Tribunal de Justiça. Recurso Especial $n^{\circ} .1713167$ SP 2017/0239804-9. https://stj.jusbrasil.com.br/jurisprudencia/63585528 6/recurso-e special-resp-1713167-sp-2017-0239804-9/inteiro-teor-635855288.

Santa Catarina (Estado). (2003). Código Estadual de Proteção aos Animais. Lei $n^{\circ} .12 .854$, de 22 de Dezembro de 2003. http://leis.alesc.sc.gov.br/html/2003/12854_2003_Lei.html.

Singer, P.(2002). Vida Ética. Ed. Ediouro.

Tobbin, R. A. \& Cardin, V. S. G. (2020). Família Multiespécie: a tutela jurídica dos animais e os direitos de guarda, visitação e alimentos. In: Vieira, T. R. \& Silva, C. H. Família Multiespécie Animais de Estimação e Direito. Ed. Zakarewicz. 139-55.

Valle, A. C. N. A. \& Borges, I. F. B. (2018). A guarda dos animais de estimação no divórcio. Academia de Direito Civil, 3, 1-23.

Vieira, T.R. \& Silva, C. H.(2016). Animais Bioética e Direito. Ed. Zakarewicz. 